\title{
D-Dimer Testing in Pregnancy
}

\author{
Sabine Eichinger
}

Dept. of Internal Medicine I, Div. of Hematology and Hemostasis, Allgemeines Krankenhaus Wien, Austria

\section{Key Words}

D-Dimer · Pregnancy

\begin{abstract}
During pregnancy, elevated markers of coagulation and fibrinolytic system activation, such as D-Dimer, indicate increased thrombin activity and increased fibrinolysis following fibrin formation. Testing for D-Dimer during pregnancy could therefore be useful for the diagnosis and prediction of a venous thromboembolic event (VTE) or pregnancy-related complications, and for monitoring antithrombotic treatment. This approach, however, is hampered by the fact that even an uncomplicated pregnancy in healthy women is accompanied by a substantial increase of D-Dimer. Thus, prior to clinical application reference values of D-Dimer according to gestational age need to be established. A substantial increase of D-Dimer during pregnancy is seen despite thromboprophylaxis with low molecular weight heparin (LMWH) indicating that further studies are needed to evaluate monitoring of LMWH during pregnancy and to investigate the optimal beginning and dose of LMWH thromboprophylaxis in pregnant women.
\end{abstract}

Copyright @ 2004 S. Karger AG, Base

\section{KARGER}

Fax +4161306 1234

E-Mail: karger@karger.ch www.karger.com
(C) 2004 S. Karger AG, Basel 1424-8832/04/0336-0327\$21.0/0

Accessible online at: www.krager.com/pht
During normal pregnancy both the risk of bleeding and of thrombosis are increased. While bleeding complications mainly occur during or after delivery, the risk of thrombosis is increased throughout pregnancy and is particularly high after delivery. Altered rheology, vascular injury, impaired fibrinolysis and a hypercoagulable state contribute to the increased risk of venous thrombosis. This is also reflected by various alterations of the hemostatic system which occur during normal pregnancy, such as elevated levels of factors VII, VIII, X and von Willebrand antigen [1]. In addition, we have demonstrated that even uncomplicated pregnancy is accompanied by a substantial hemostatic system activation as indicated by an increase in the plasma concentration of coagulation activation markers, such as prothrombin fragment F1+2 and D-Dimer [2].

The elevated levels of D-Dimer during pregnancy may reflect (1) increased coagulation activation and thrombin generation, (2) increased fibrinolysis, or (3) a combination of both. Consequently, testing for D-Dimer during pregnancy could be useful for the diagnosis and prediction of a venous thromboembolic event (VTE) or pregnancy-related complications, and for monitoring antithrombotic treatment.

\section{Diagnosis of Venous Thromboembolism}

Although D-Dimer testing has a prominent role in the exclusion of acute venous thrombosis in the non-pregnant

Sabine Eichinger, MD

Dept. of Internal Medicine I

Div. of Hematology/Hemostasis

Allgemeines Krankenhaus Wien

A-1090 Wien, Austria

Tel. +43-1-40400-4410; E-mail: sabine.eichinger@meduniwien.ac.at 
population [3, 4], incorporating D-Dimer in algorithms for diagnosing VTE in pregnant women has not been adequately studied. This approach is mainly hampered by the fact that even during an uncomplicated pregnancy in healthy women D-Dimer levels increase with gestational age [2, 57]. Therefore, prior to clinical application, reference values for D-Dimer according to gestational age need to be established. These reference values need to be calculated in an adequate number of healthy pregnant women of different gestational weeks [8]. Subsequently, the specificity and sensitivity of various cut-off levels of D-Dimer for the diagnosis of VTE during pregnancy need to be tested. As long as these data are not available, D-Dimer has very limited value in the diagnosis of venous thrombosis during pregnancy.

\section{Prediction of Venous Thromboembolism}

Although infrequent, VTE during pregnancy is an important cause of maternal death in the industrialized world. Women with prior VTE are believed to have a higher risk of VTE in a subsequent pregnancy. Currently, there are only two studies, in which the risk of recurrence and the association with potential risk factors have been evaluated $[9,10]$. In the prospective study, the frequency of antepartum recurrences was $2.4 \%$ [9]. In neither of the two studies, a clear prediction of women at risk by testing for traditional thrombophilic risk factors was possible. D-Dimer is a good predictor of recurrent venous thromboembolism in nonpregnant patient cohorts $[11,12]$. Low levels of D-Dimer were associated with a $60 \%$ reduction of the relative risk of recurrence compared to patients with higher levels which was independent of other thrombotic risk factors [12]. Importantly, the prevalence of markers of thrombophilia, such as factor V Leiden, prothrombin G20210A, or high factor VIII, was significantly higher among patients with high D-Dimer as compared with those with low levels. Thus, DDimer testing during pregnancy could be useful to identify women at high risk of (recurrent) venous thrombosis. Adequately designed studies are warranted to investigate this issue and the timing of D-Dimer testing as well as the appropriate cut-off levels in pregnant women.

\section{Diagnosis and Prediction of Pregnancy Related Complications}

Several studies have investigated whether pregnancy related complications, such as gestational hypertension [13] and diabetes [14], preeclampsia [15, 16], or abruptio placentae [17], are associated with changes in hemostatic parameters. Interpretation of the studies, however, is limited by several facts: (1) pregnancy related complications comprise a variety of clinical entities, which often leads to the inclusion of inhomogeneous patient cohorts, (2) the number of patients in these studies was small as was the number of controls, (3) since reference values of D-Dimer during normal pregnancy are not available, the specificity of D-Dimer for diagnosing and predicting pregnancy related complications is reduced.

\section{Monitoring of Antithrombotic Treatment}

Several studies indicate that low-molecular weight heparin (LMWH) is safe and effective during pregnancy [18-20]. Clinical thromboprophylactic as well as therapeutic trials comparing LMWH and unfractionated heparin included many thousands of patients and were safely conducted without monitoring LMWH. Summarizing the results of these studies, monitoring of LMWH by measuring anti-Xa levels did not improve the safety and efficacy of LMWH. In addition, anti-Xa measurement in plasma has potential pitfalls, such as the different anti-Xa/anti-IIa ratios of the LMWH preparations, or the timing of blood sampling. There are, however, some situations including over- or underweight patients or renal insufficiency, in which monitoring of LMWH is recommended. During pregnancy, the need to adapt LMWH to the weight of the pregnant woman has never been studied in appropriate trials and remains controversial. In addition, firm recommendations with regard to either the timing of the monitoring or adapting the dosage of LMWH are not available.

In a prospective study, we measured D-Dimer throughout pregnancy in women who received LMWH thromboprophylaxis and in healthy pregnant controls [21]. Despite LMWH, activation of the coagulation system was already seen during the early course of pregnancy, and further substantial coagulation activation occurred with advancing pregnancy. One of 61 women who received LMWH after previous VTE had recurrence. Further studies are needed to evaluate monitoring of LMWH during pregnancy and to investigate the optimal beginning and dose of $\mathrm{LMWH}$ thromboprophylaxis in pregnant women. 


\section{References}

1 Hellgren M. Hemostasis during normal pregnancy and puerperium. Semin Thromb Hemost 2003; 29:125-130.

-2 Eichinger S, Stümpflen A, Hirschl M, Bialonczyk C, Herkner K, Stain M, et al. Hyperhomocysteinemia is a risk factor of recurrent venous thromboembolism. Thromb Haemost 1998;80:566-569.

-3 Wells PS, Anderson DR, Ginsberg J. Assessment of deep vein thrombosis or pulmonary embolism by the combined use of clinical model and noninvasive diagnostic tests. Semin Thromb Hemost 2000;26:643-656.

4 Kelly J, Hunt BJ. A clinical probability assessment and D-dimer measurement should be the initial step in the investigation of suspected venous thromboembolism. Chest 2003;124:1116-1119.

5 Van Wersch JWJ, Ubachs JMH. Blood coagulation and fibrinolysis during normal pregnancy. Eur J Clin Chem Clin Biochem 1991;29:45-50.

-6 Sattar N, Greer IA, Rumley A, Stewart G, Shepherd J, Packard CJ, Lowe GD. A longitudinal study of the relationships between haemostatic, lipid, and oestradiol changes during normal human pregnancy. Thromb Haemost.1999;81(1):71-5.

7 Chabloz P, Reber G, Boehlen F, Hohlfeld P, de Moerlosse P. TAFI antigen and D-dimer levels during normal pregnancy and at delivery. $\mathrm{Br} \mathrm{J}$ Haematol 2001;115:150-152.

8 Giavarina D, Mezzana G, Dorizzi RM, Soffiati G: Reference interval of D-dimer in pregnant women. Clin Biochem 2001;34:331-333.
9 Brill-Edwards P, Ginsberg JS, Gent M, Hirsh J, Burrows R, Kearon C, et al. Recurrence of Clot in This Pregnancy Study Group. Safety of withholding heparin in pregnant women with a history of venous thromboembolism. Recurrence of Clot in This Pregnancy Study Group. N Engl J Med 2000;343:1439-1444.

10 Pabinger I, Grafenhofer H, Kyrle PA, Quehenberger P, Mannhalter C, Lechner K, Kaider A. Temporary increase in the risk for recurrence during pregnancy in women with a history of venous thromboembolism. Blood 2002;100:10601062.

11 Palareti G, Legnani C, Cosmi B, Guazzaloca G, Pancani C, Coccheri S. Risk of venous thromboembolism recurrence: high negative predictive value of D-dimer performed after oral anticoagulation is stopped. Thromb Haemost 2002;87:7.

12 Eichinger S, Minar E, Bialonczyk C, Hirschl M, Quehenberger P, Schneider B, Weltermann A Wagner O, Kyrle PA. D-dimer levels and risk of recurrent venous thromboembolism. JAMA 2003;290:1071-1074.

13 Cadroy Y, Grandjean H, Pichon J, Desprats R, Berrebi A, Fournie A, Boneu B. Evaluation of six markers of haemostatic system in normal pregnancy and pregnancy complicated by hypertension or pre-eclampsia. $\mathrm{Br} \mathrm{J}$ Obstet Gynaecol 1993;100:416-420.

14 Bellart J, Gilabert R, Fontcuberta J, Carreras E, Miralles RM, Cabero L. Coagulation and fibrinolysis parameters in normal pregnancy and in gestational diabetes. Am J Perinatol 1998;15:479-486.
16 Proietti AB, Johnson MJ, Proietti FA, Repke JT, Bell WR. Assessment of fibrin(ogen) degradation products in preeclampsia using immunoblot, enzyme-linked immunosorbent assay, and latexbased agglutination. Obstet Gynecol 1991;77:696700 .

17 Bellart J, Gilabert R, Angles A, Piera V, Miralles RM, Monasterio J, Cabro L. Tissue factor levels and high ratio of fibrinopeptide A: D-dimer as a measure of endothelial procoagulant disorder in pre-eclampsia. $\mathrm{Br} \mathrm{J}$ Obstet Gynaecol 1999;106:594-597.

18 Nolan TE, Smith RP, Devoe LD. A rapid test for abruptio placentae: evaluation of a D-dimer latex agglutination slide test. Am J Obstet Gynecol 1993;169:265-8; discussion 268-269.

19 Brenner B, Hoffman R, Blumenfeld Z, Weiner Z, Younis JS: Gestational outcome in thrombophilic women with recurrent pregnancy loss treated by enoxaparin. Thromb Haemost 2000;83:693-697.

20 Hunt BJ, Doughty HA, Majumdar G, Copplestone A, Kerslake S, Buchanan N, Hughes G, Khamashta Ml. Thromboprophylaxis with low molecular weight heparin (Fragmin) in high risk pregnancies. Thromb Haemost 1997;77:39-43.

21 Carp H, Dolitzky M, Inbal A. Thromboprophylaxis improves the live birth rate in women with consecutive recurrent miscarriages and hereditary thrombophilia. J Thromb Haemost 2003;1:433438.

22 Hoke M, Kyrle PA, Philipp K, Pabinger I, Kaider A, Schönauer V, et al. Prospective evaluation of coagulation activation in pregnant women receiving low-molecular weight heparin. Thromb Haemost 2004;91:935-940. 